\title{
The Evolution of a Professional Identity as Perceived by Saudi Student Nurses
}

\author{
Shehnaaz Moola ${ }^{1,2}$ \\ ${ }^{1}$ PhD., Department of Health Studies, University of South Africa, South Africa \\ ${ }^{2}$ Nursing Department, King Saud Bin Abdulaziz University for Health Sciences, Jeddah, KSA \\ Correspondence: Shehnaaz Moola, Nursing Department, King Saud Bin Abdulaziz University for Health Sciences, \\ P.O. Box 9515, Jeddah 21423, KSA. Tel: 966-12-224-6666 Ext. 46253; 966-050-701-6454. E-mail: \\ shenazy28@yahoo.co.uk
}

Received: May 12, 2017 Accepted: September 12, 2017 Online Published: December 18, 2017

doi:10.5539/gjhs.v10n2p1 URL: https://doi.org/10.5539/gjhs.v10n2p1

\begin{abstract}
The professional identity of student nurses may fluctuate or even disintegrate when exposed to clinical realities. A self-identity must be integrated firstly with new expectations and modified within a social context to form a professional identity. In the process of developing a professional identity, student nurses either develop a self-concept within a professional role based on attributes, beliefs, values, motives, experiences, morals and ideals of who and what a nurse is, or lack to develop in this role. This study targeted to investigate the perceptions of Saudi student nurses in the evolution of a professional identity. A non-probabilistic and descriptive approach was selected for data collection. A Nurses Professional Identity Scale was constructed by the researcher to explore the evolution of a professional identity as perceived by Saudi student nurses. Mean scores indicated the importance of the self-presentation, self-image, self-esteem, self-categorization and self-concept as dimensions, which facilitates a professional identity. The p-values obtained for all the factors were less than the level of significance (p-value $<0.05$ ), which indicated the importance of all the associated factors. The significance of how student nurses identify themselves as professionals during the Baccaulearate program in various role formation has been emphasized. These roles are still undervalued by society and influences stereotypical attitudes.
\end{abstract}

Keywords: student nurse, evolution, professional identity and baccaulearate nursing program

\section{Introduction}

\subsection{Introduction to the Problem}

Nursing colleges are evaluated by the quality of knowledge and clinical training offered to the students. Minimal attention has been given to the value, behavior, and attitudes, which are essential to assume a professional identity in the nursing role of Saudi nurses. New graduates assumed that they are professional, competent, valued and respected, but realized that there is a lot more than just being educated. This study has envisioned to inspect the socio-psycho constructs besides a cognitive component to evaluate how Saudi student nurses form a professional identity. The purpose of the study was to deliver a mechanism for sharing awareness related to enlightening healthcare and supporting the development of nursing. The objective of this research was to describe the evolution of a professional identity as perceived by Saudi student nurses during their Baccalaureate Nursing Program. Lack of clear understanding about professional identity within the nursing profession has led to explore the structural and macro-sociological phenomena regarding the attitudes and behaviors of nursing students in Saudi Arabia. The spontaneous willingness to become a nurse and to stay in the nursing profession are somehow associated with nursing education. In order to signify the concerns regarding the willingness to become a nurse among the nursing students, the behaviors and attitudes of nursing students have been the focus. The concepts of student nurse, evolution, professional identity, and Baccalaureate program in the study have been identified below:

Student Nurse: A student nurse is a pre-registered undergraduate student from an accredited baccaulearate nursing program (author).

Evolution: It develops overtime from ancient to present times (Brooks \& Kleine-Kracht, 1983).

Professional Identity: It is a sense of 'self' that connects the professional role to a particular occupation or career (Adams \& Miller, 2001). In this study, a professional identity is referred as the perceptions of Saudi student nurses 
in the construction of a professional identity.

In this study a Baccalaureate Program, runs over a 4 year period, and is an undergraduate program for Saudi student nurses in Saudi Arabia.

\subsection{Importance of the Problem}

Crigger and Godfrey (2014) defined professional identity as a dynamic process, which commences in undergraduate nursing education and evolves by developing students' into proficient and practical career oriented nurses. The motivation to conduct the study was the requirement for exploring the evolution of a professional identity among Saudi student nurses. Furthermore, it highlighted how student nurses perceive themselves in the context of the social environment within which they interact. Traditional, social, and cultural values determined how the public perceive the nursing profession and how nurses perceive themselves in light of being compatible with other professions (Hoeve et al., 2014). Nurses usually work hard to interconnect their professionalism with the public. The study has intended to assess the perceptions of Saudi student nurses on how a professional identity has been developed, which can be considered as a significant factor to be explored. The objective of this study is to describe the evolution of a professional identity as perceived by Saudi student nurses during their Baccalaureate Nursing Program. The general objectives aim towards answering the following questions:

1). How do student nurses perceive their professional identities?

2). How do various levels of students' education influence a professional identity?

3). Which dimensions of a professional identity significantly contribute to students' development?

\subsection{Relevant Scholarship}

Professionalism is the extent to which an individual identifies with a profession and adheres to its standards. A nursing profession comprises of several roles that have been socially defined (Adams \& Miller, 2001). According to Willetts and Clarke (2014), the nursing profession has continued to struggle in terms of outlining and illuminating its professional identity. The professional identity of student nurses may fluctuate or even disintegrate when exposed to clinical realities in recognizing the nursing profession. A self-identity must be integrated firstly with new expectations and modified within a social context to form a professional identity (Felstead, 2013).

Student nurses have a vision of how they perceive themselves as professionals (Larson et al., 2013). In the process of developing a professional identity, student nurses either develop a self-concept within a professional role based on attributes, beliefs, values, motives, experiences, morals and ideals or are unable to develop in this role (Crigger \& Godfrey, 2014). Robert (2000) suggested that a major factor that keeps the oppressed nurses from becoming empowered is poor self group esteem and identity. Many studies have explored nursing as a struggling profession. The nursing as a profession continues to make effort with clarifying and defining its professional identity as compared to any other profession (Willetts \& Clarke, 2014). It has been indicated that nurses lack to define their work parallel to other professions (Adams \& Miller, 2001; Willetts \& Clarke, 2014; Fielden, 2012). Franco and Tavares (2013) describe nurses to believe "They have their own identity that differentiates them from other healthcare professionals; however, they considered that their work still lacks socio-professional recognition". In Saudi Arabia, the association of women to the profession of nursing is increasing; however, the barriers that impede the development of a professional identity in the chosen profession have also increased. In order to be accepted by all facets of society, Saudi nurses are expected to prove that they can work within Islamic boundaries and uphold traditional family honor within a professional identity (Mebrouk, 2008).

The proportion of Saudi emigrant nurses working in the health care sectors raised from 9\% in 1966 to $21.5 \%$ in 2002 and $29.1 \%$ in 2008. In a study survey done by Al-Ahmadi (2014), 5,423 nurses in eighty hospitals and twelve regions were carried out. Factors that influenced the high turnover of Saudi nurses among others were related to the clinical realities of the environment, the working hours, and the image of nursing as compared to other professions.

Pordanjani et al. (2014) explored the effects of professional identity formation of student nurses in the clinical environment by using a qualitative approach. It revealed the theme as 'damaged professional identity' and further sub-categorized it as 'trampled individual and social statuses. The study emphasized on the nurses' inability to make their voices heard (Baraz-Pordanjani et al., 2014). A doctoral thesis on measuring professional identity highlighted that a transformation should exist in a way that an individual presents himself to others and to oneself within the learning process of formal nursing education (ten Dam \& Blom, 2006).

Hao et al., (2014) in a study of Chinese nurses displayed a low professional identity, a proficient self-concept of nursing, which represented the views of nursing students about nursing profession. Results indicated that early conceptualisation of a professional identity can improve the quality, image, and retention of the nurses. In an 
integrated study of Reid, et al. (2009), it has been identified that the teaching process and curriculum development contribute to student's professional formation. It enhances the readiness in the professional role and defines the intellect of the profession, which was transferred and expressed through the pedagogy and design of the educational programme. In an attempt to identify with a profession, professional identity focuses on the academic preparation of student nurses, as well as the exploration of social performance of people within their professional learning environment. This aspect enhances the understanding of a professional identity in nursing overtime (Willetts \& Clarke, 2014). New expectations must be integrated through observation of the nursing role and the total self-identity must be modified to encompass a professional identity. Willets and Clarke (2014) suggested that through applying the social identity Theory to the nursing profession, nurses would develop a fuller understanding of their own professional identities.

A theoretical framework has been introduced which identifies factors that form an integral part of the nursing profession. The theoretical framework has been selected to identify the nursing profession along with the influencing factors as shown in figure 1. This specific framework has been proposed to justify the emergence of nursing as a profession and development of nurses' professional identity. Almost all the factors have been included in the framework, which were essential to summarize the concept of the study.

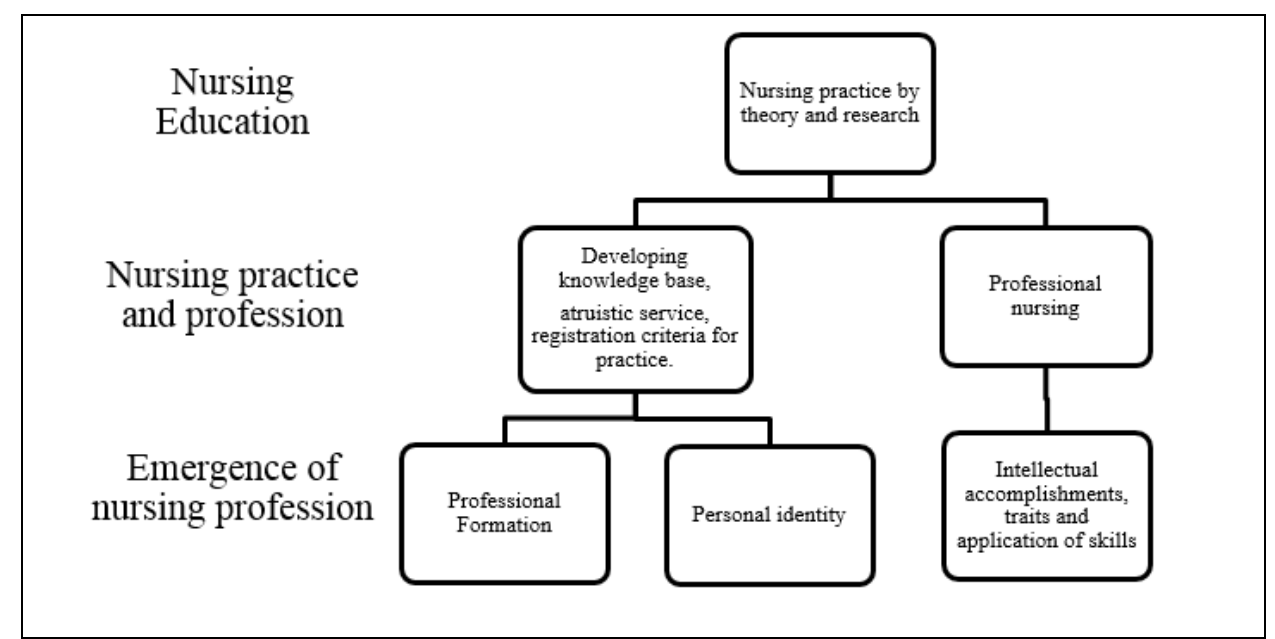

Figure 1. Theoretical Framework: Describes the Nursing Profession as a part of Nursing Education, and Clinical Practice

The emergence of nursing as a science started in the $20^{\text {th }}$ century, nursing practice was determined by theory and research. It has been considered that research without theory created isolated information. Nursing, at this phase, had achieved various individualities of a profession, developed knowledge based authority over training and education, atruistic service, code of ethics and registration criteria for practice. Thus, professional nursing is a combination of intellectual accomplishments, traits, and application of skills confirmed by registration authorities for practice (McEwen \& Wills, 2002). In speculation "what is needed is an open philosophy that ties empirical concepts with the theoretical concepts to provide meaning and value" (McEwen \& Wills, 2002). Influenced by a myriad of factors associated with demography, economy, education, nurse leaders and theorists, religion and wars, in which nursing will continue to evolve.

The most influential theory for this study is the Social Identity Theory of Tajfel and Turner, (1986) articulated that human interaction varies between being purely interpersonal to purely intergroup. An association of individualizing qualities may exist, which may prevail over the salience of group membership of individuals, who may perceive themselves and each other as belonging in the process of professional formation. The Social Identity Theory is referred as the portion of an individual's self-concept, which relied on the relevance and importance employed on the group membership to which an individual belongs (Tajfel \& Turner, 1986).

Turner and Tajfel, (1986) identified three levels of categorization, which mainly included the superordinate level, the self as a human being, and an individual who has a personal identity. The second aspect was based on an intermediate level; the individual is perceived as a member of a social group or in-group, by ethnicity, race, skills, knowledge, training, or profession as compared to the third level. The sub-ordinate level comprised of the 
out-groups or other professions, which were compared by inter-personal similarities and differences as perceived by the personal identity.

\section{Method}

In this study, a non-probabilistic and descriptive research approach was selected for the data collection. A Nurses Professional Identity Scale was constructed, which studied the evolution of a professional identity as perceived by Saudi student nurses (Moola, 2017). The self-developed structured questionnaire developed used the Social Identity Theory described by Tajfel \& Turner (1986). The questionnaire was pilot-tested to ensure the reliability of the questionnaire. The questionnaire was developed in two languages; including English and Arabic. Arabic questionnaire was developed with the assistance of Arabic professor of King Saud Bin Abdulaziz University. It was developed for the Arabic participants to have questionnaire filled with complete clarification (Moola, 2017)

\subsection{Research Settings}

This study was conducted at the King Saud Bin Abdulaziz University (for Health Sciences) College of Nursing-Jeddah (KSAU-CON-J) affiliated with National Guard Health Affairs -NGHA, King Khalied Hospital for Health Sciences (KKH-S) and King Saud Bin Abduldaziz, Al-Hasa (KSAU-CON-A), during the period 2014 -2015 .

\subsection{Participant Characteristics}

Data analysis was done for a total number of 442 nursing students. Data analysis was targeted at:

- Testing the questionnaire for reliability and validity

- The evolution of a professional identity as perceived by Saudi Student Nurses

The reliability and validity of the questionnaire were assessed through Statistical Software of Social Science (SPSS). The Cronbach's Alpha test was applied on the data collected in the pilot study, which confirmed the reliability and validity of the questionnaire. Different levels of nursing students were selected: Junior, Senior and Intern nurses, who were enrolled in the different courses, including Fundamentals I and II; Medical/Surgical I and II; Pediatric, Maternity, Community, Psychiatric and Critical Care Nursing. The College of Nursing offers two undergraduate (Baccalaureate) Programs in Nursing Science: the first being stream I; enrolling high school graduates from level 1 to level 8. Stream II included university graduates of Chemistry, Biochemistry, Science, Physics or Mathematics, who choose Nursing as a second career, they include Levels zero to level five. This program extends over a period of 4 years. The two programs are preceded by a fundamental program. The purpose of the program is to develop and graduate competent and safe nurse practitioners. Nurses were selected randomly, and the study period was from 2014 to 2015 . The nurses recruited in the study were then provided with the informed consent form, which ensured that all the information gathered from them will be kept private and confidential. A total of 460 questionnaire were distributed among the participants from which 442 were received completely filled. The ethical approval was taken from the research committee of the university.

\subsection{Sampling Procedures}

To minimize any bias in the data collection, it was ensured that the data-collection process has been standardized. The respondents received standardized instructions on how to complete the questionnaires. The questionnaire packages were distributed to the designated persons at CON-J, NGHA, as well as the Basic Sciences of KSAU and CON-A. Translation of the instrument into Arabic was done by a peer researcher to further facilitate comprehension of the instrument, as English was not the first language of the respondents. Each questionnaire undertook at least 20 minutes to complete under the supervision of a researcher or designated person. Data collection was done over a four week period from, $\mathrm{n}=442$ respondents respectively.

\subsection{Data Analysis}

Descriptive statistics were calculated to give a description of the biographical characteristics of the respondents. The concept of the social identity theory (Tajfel \& Turner, 1979,1986) has been measured, using a 4 point likert scale, which indicated Strongly Agree $=4$; Agree $=3$; Disagree $=2$ and Strongly disagree $=1$. In addition to this, a descriptive, correlational analysis was implemented, using Pearson's correlational analysis technique. This approach was applied to establish the existence of significant comparisons and the relationships between and among the variables and potential practical indicators in the context of nursing and assist in the educational environment of facilitation and learning.

Table 1 showed the demographic data obtained from the participant nurses. SPSS version 20 was used for statistical analysis of numerical data. Descriptive statistics (i.e. mean, median and standard deviation scores), 
MANOVA, ANOVA and Hotellings $\mathrm{T}^{2}$ have been applied to measure the mean and median scores and correlational tests to compare demographical data with various dimensions and factors in the questionnaire. Significance was set at $\mathrm{P}<0.05$ and cutoff point for the scales was 3 .

Table 1. Demographic Profile

\begin{tabular}{lllll}
\hline Characteristic & $n$ & $\%$ & Cumulative Frequency & Cumulative Percent \\
\hline Age in Years & 360 & 81.45 & 360 & 81.45 \\
19 - 24 years & 82 & 18.55 & 442 & 100.00 \\
25 - 30 years & & & & \\
Number of Children & 406 & 91.86 & 406 & 91.86 \\
None & 33 & 7.47 & 439 & 99.32 \\
$1-2$ Children & 3 & 0.68 & 442 & 100.00 \\
Above 4 children & & & & 47.96 \\
Juniors, Seniors \& Interns & 212 & 47.96 & 212 & 89.59 \\
Juniors & 184 & 41.63 & 396 & 100.00 \\
Seniors & 46 & 10.41 & 442 & \\
Interns & & & & \\
\hline
\end{tabular}

\section{Results}

Table 2 identified the basic descriptive statistics for the average score of each of the five factor dimensions as shown in Table 2. The mean scores (x) of Factor 1 scored the highest in terms of significance to Self-Presentation $(x=3.7)$ than the other 4 factors. Factor 5 was the second highest $(x=3.6)$ and was significant to a Self-Concept. Factor 2 was the third highest $(x=3.5)$ and scored significantly and equal to a Self-image $(x=3.5)$. Factor 4 scored fourth highest $(\mathrm{x}=3.46)$ and was significant to Self-Categorization. Factor 3 scored the fifth highest $(\mathrm{x}=2.51)$ and was significant to a Self-Esteem.

The analysis of variance (ANOVA) was carried out to compare the mean with mean scores. The Tukey's student range was used for the multiple means, for factor 1 of the different marital status levels, at a $5 \%$ level of significance $n=72$ married with a mean of 3.5 and $n=370$, who are single with a mean score of 3.5 .

The mean scores of 25-30 years old respondents with variables in F2 and F4, was more than with respondents of 19-24 years. Respondents having 1-2 children, disagreed on an average more with variables in F4 than those, who have no children. Since all p-values are less than 0.05 , the null hypothesis was rejected and concluded that the study level has a significant overall effect on the 5 mean factor scores at a $5 \%$ level of significance. It implies that the mean factor scores differ significantly for different study levels and confirms the univariate results (Nishisato, 1980).

Table 2. Description of i) mean of the mean scores, ii) ANOVA Results, iii) ANOVA Test Criteria and iv) MANOVA Tests

\begin{tabular}{lllllll}
\hline Factor & Mean & Median & Std & Min & Max & Score \\
\hline Mean Factor 1 & 3.66 & 3.76 & 0.35 & 2.15 & 4 & 1 \\
Mean Factor 2 & 3.53 & 3.63 & 0.42 & 1.81 & 4 & 3 \\
Mean Factor 3 & 2.515 & 2.42 & 0.67 & 1.00 & 4 & 5 \\
Mean Factor 4 & 3.46 & 3.50 & 0.42 & 1.00 & 4 & 4 \\
Mean Factor 5 & 3.60 & 3.75 & 0.44 & 2.00 & 4 & 2 \\
\hline
\end{tabular}


Multivariate Analysis

\begin{tabular}{|c|c|c|c|c|c|}
\hline Statistics & Value & $\mathrm{F}$ Value & Num DF & Den DF & $\operatorname{Pr}>F$ \\
\hline \multicolumn{6}{|l|}{ Number of Children } \\
\hline Wilks' Lambda & 0.97 & 1.87 & 5 & 431 & 0.09 \\
\hline Pillai's Trace & 0.02 & 1.87 & 5 & 431 & 0.09 \\
\hline Hoteling - Lawley Trace & 0.02 & 1.87 & 5 & 431 & 0.09 \\
\hline Roy's Greatest Root & 0.02 & 1.87 & 5 & 431 & 0.09 \\
\hline \multicolumn{6}{|l|}{ Juniors, Seniors \& Interns } \\
\hline Wilks' Lambda & 0.94 & 2.27 & 10 & 862 & 0.01 \\
\hline Pillai’s Trace & 0.05 & 2.27 & 10 & 864 & 0.01 \\
\hline Hoteling - Lawley Trace & 0.05 & 2.27 & 10 & 643.76 & 0.01 \\
\hline Roy's Greatest Root & 0.03 & 2.27 & 5 & 432 & 0.009 \\
\hline
\end{tabular}

The MANOVA test has taken the intercorrelations of dependent variables into account. The age effect is partially supported by the following MANOVA test at a 5\% level of significance. There was no difference between ages 25-30 years and 19-24 years when considered jointly on the variables in factor 2 and factor 4, taking Hotelling or Wilk's Lambda A $=0.97 ; \mathrm{F}-1.87=5 ; \mathrm{P}=0.09 ; \mathrm{P}=\mathrm{n}^{2}$.

Respondents having 1-2 children, disagreed on an average more with variables in F4 than those, who have no children. Since all p-values are less than 0.05 , the null hypothesis was rejected and concluded that the study level has a significant overall effect on the 5 mean factor scores at a $5 \%$ level of significance and implies that the mean factor scores differ significantly for different study levels and confirms the univariate results. Four different tests were applied including Wilks'Lambda, Pillai's Trace, Hotelling-Lawley trace and Roy's Greatest Root and the pvalues remain the same at 0-09 for all tests applied.

Table 3 indicates that Interns tend to disagree on average more with the questions in F3, self -esteem, than the senior and junior Students, While Junior seem to disagree more with questions in factor 5 on Self-Concept than Seniors and was supported by the following MANOVA test. There was a significant difference at $5 \%$ level between Interns on $\mathrm{F} 3$, self-esteem than senior and junior students, when considering jointly on the variable F3, taking Wilks' Lambda $\mathrm{A}=0.9 ; \mathrm{F}=2.27=10 ; \mathrm{P}=0,127 ; \mathrm{p}=\mathrm{n}^{2}$. There was a significant difference at a $5 \%$ level of significance between junior nurses, when they disagreed more in questions in F5=Self-Concept. The participants having 1 or 2 children, disagreed on average more with the questions in factor $4=$ Self-Categorization than the participants, who have no children.

Table 3. Paired t-test

\begin{tabular}{|c|c|c|c|c|}
\hline \multirow{2}{*}{ Item } & \multirow{2}{*}{ Difference Between Means } & \multicolumn{2}{|c|}{ Simultaneous 95\% Confidence Limits } & \multirow{2}{*}{ Significance } \\
\hline & & Lower Limits & Upper Limits & \\
\hline \multicolumn{5}{|l|}{ Number of Children } \\
\hline 1-2 Children vs. None & 0.18 & 0.007 & 0.36 & $* * *$ \\
\hline 1-2 Children vs. Above 4 Children & 0.30 & -0.29 & -0.90 & \\
\hline none vs. 1 - 2 Children & -0.18 & -0.36 & -0.007 & $* * *$ \\
\hline None vs. Above 4 Children & 0.11 & -0.46 & 0.69 & \\
\hline Above 4 Children vs. $1-2$ children & -0.30 & -0.90 & 0.29 & \\
\hline Above 4 Children vs. None & -0.11 & -0.69 & 0.46 & \\
\hline \multicolumn{5}{|l|}{ Juniors, Seniors \& Interns } \\
\hline Interns vs. Seniors & 0.26 & 0.0009 & 0.51 & $* * *$ \\
\hline Interns vs. Juniors & 0.27 & 0.01 & 0.53 & $* * *$ \\
\hline
\end{tabular}




\begin{tabular}{lllll}
\hline Seniors vs. Interns & -0.26 & -0.51 & -0.0009 & $* * *$ \\
Seniors vs. Juniors & 0.01 & -0.14 & 0.17 & $* * *$ \\
Juniors vs. Interns & -0.27 & -0.53 & -0.01 & \\
Juniors vs. Seniors & -0.01 & -0.17 & 0.14 & \\
Interns vs. Juniors & 0.03 & -0.13 & 0.20 & \\
Interns vs. Seniors & 0.14 & -0.02 & 0.32 & $* * *$ \\
Juniors vs. Interns & -0.03 & -0.20 & 0.13 & \\
Juniors vs. Interns & 0.11 & 0.004 & 0.21 & $* * *$ \\
Seniors vs. Interns & -0.14 & -0.32 & 0.02 & \\
Seniors vs. Juniors & -0.01 & -0.21 & -0.004 & $*$ \\
\hline
\end{tabular}

The inter-factor correlations are those with correlations greater than 0.2 and bounded by (-1 and 1) i.e. between Factors 1= Self Presentation and Factor 2=Self-Image; Factors 1 and Factor 4; Factors 2 and Factor 4; and Factors 2 and Factor $5=$ Self-Concept.

Figure 2 indicates a Multiple correspondence analysis plot on how the different levels of the demographic information interact with each other. Such as singles and those having no children seem to lie close (Nishisato, 1980).

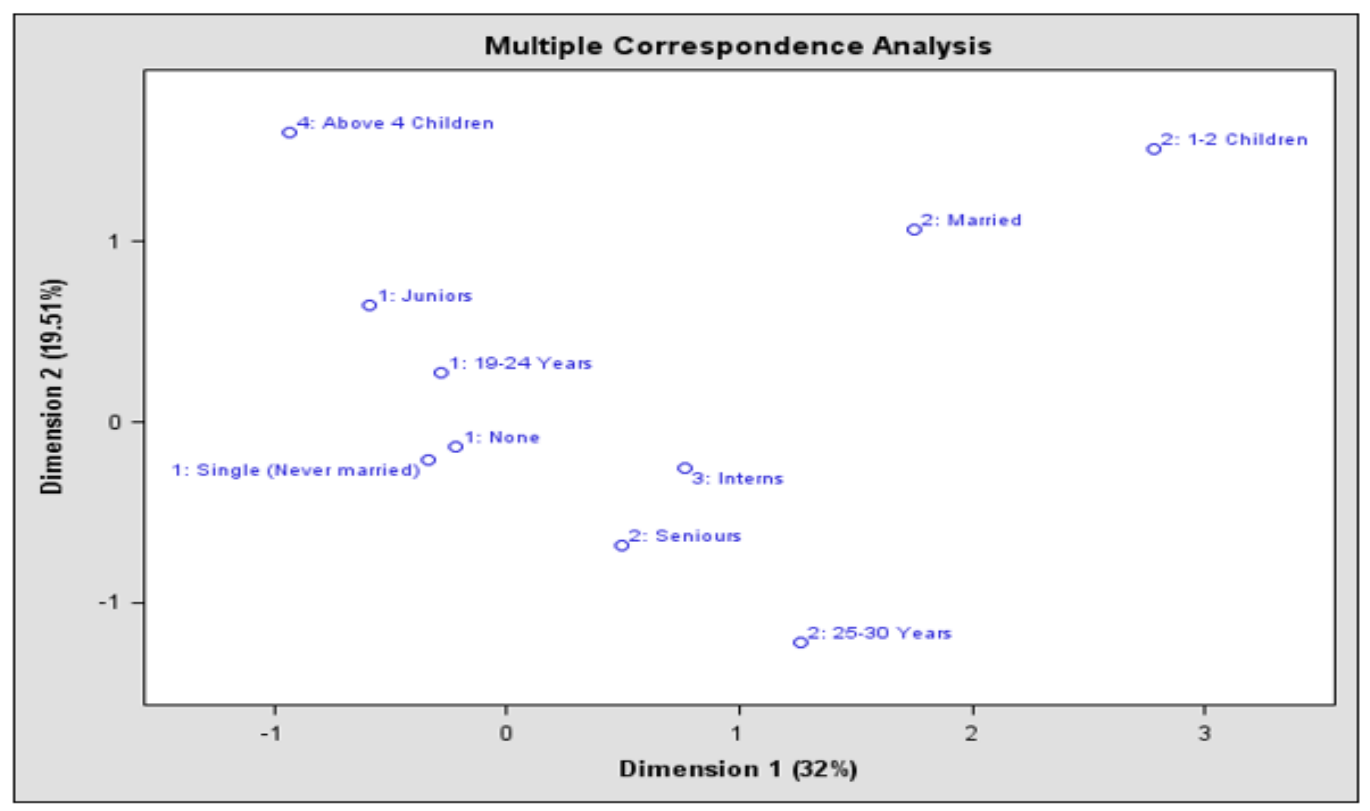

Figure 2. Multiple Correspondence Analysis

\section{Discussion}

This study used the Social Identity theory of Tajfel \& Turner, (1986) and Tajfel \& Turner, (1979) throughout as the theoretical framework for a nurse's professional identity. In summary, student nurses perceived Factor $=1$ on self-presentation as most significant and central to the process of constructing and forming a professional identity. Hoeve et al. (2014) supported that it is imperative for nurses as a group to establish a professional image and present themselves as professionals. Factor $=2$ on Self-Image was perceived and scored second. The current results indicated that students, who were 25-30 years old disagreed on an average more with the variables in F2 than younger students of 19-24 years. It may be suggested that students on an entry level are likely to answer positively. On the other hand, the atmosphere at group level with the students of 19-24 years led to a positive self-esteem at group level enhancing a collective self-image. Students 25-30 years either majored in sciences, such as Biology, 
Mathematics, Chemistry and Bio-chemistry, etc. selected to choose these careers out of choice or due to family approval. Results suggested that respondents in this group were not able to get jobs in these careers and opted for a nursing career instead.

Social identity theorists proposed that there are high and low identifiers within a group, low identifiers discriminate and exit the group eventually. In-group favoritism exists due to different perspectives (Abdelal et al., 2001). Individuals, who have very low self-esteem, lack self-confidence to enhance via group discrimination, but enhance more with out-group derogation (Hewstone \& Brown, 1986). Students interest in being recruited, but the inadequate socialization process can result in these problems. The question arises how does public image rise over time? Student nurses evaluate the group in reference to out-groups in forming a self-concept. A statistically significant difference resulted between the mean scores for factor 3 on Self Esteem. Interns disagreed more than junior and senior students at a $\%$ level of significance. From the social identity perspective interns have motivated a shared self-esteem within the group, which motivated a shared self-image of the nursing profession. Juniors and seniors are still in the process of self-evaluating their experiences over time. The SIT group level concept of social self-esteem of positive distinctiveness reinforces the idea that individuals strive for positive self-esteem as group members rather than as individuals (Hewstone \& Brown, 1986). The mean scores of respondents having 1-2 children disagreed more with variables in Factor 4 on Self-Categorization, than respondents, who had no children.

These results suggested that respondents with children identified much more stability within the nursing profession and felt a 'belonging' and a 'social identity'. Strong comparisons to the out-group suggested a positive self-esteem in establishing a greater group identity, which affirms a social identity. It may be suggested that respondents without children may not have affirmed a social identity yet, or may move in social mobility. Social identity proposes that they feel devalued due to the in-group differences and move to a perceived higher status group (Ellemers \& Haslam, 2011). The results observed no significant differences between the mean scores for the different marital status at a $5 \%$ level of significance of factor 4 on Self-Categorization. The results suggested that self- categorization is enhanced when individuals decide to enter a specific group such as a group of student nurses. These respondents identified the members in their group. This falls in line with the social identity hypothesis that they feel a sense of 'belonging' and identified the group even though nursing at its most basic level compare social concept with others. The results identified no difference between the mean scores for factor 2 on Self-Image for the different study levels at a 5\% level of significance. Junior students tend to disagree more with questions in Factor 5 than seniors, which suggested that junior students have not identified a professional Self-Concept. In light of the Social Identity Theory, a positive Self-Esteem is motivated by the in-group members in enhancing the image of nursing. However, people measure self-esteem on an individual level and expect group outcomes. Juniors might still feel insecure in having a Self-Concept. Tzeng (2006) stated that nurses positive or negative self-concept and presentations influences public perception negatively or positively. The factors that were predisposed by the demographic characteristics can be described in the evolution of a professional identity, such as age and findings confirmed that younger students needed to fulfill the professions' norms, values and standards and were still in the process of developing a self-concept.

The present study has explored the preparation of student nurses in the bacculaureate program, which facilitates various role formation, however these roles are still undervalued by society and this influences stereotypical attitudes. The findings of this study indicated the significance of how student nurses identify themselves professionally. In turning around negative stereotypical attitudes by a professional self-presentation, people can change their views and perceptions overtime. The findings further confirmed that a positive self-presentation portrays a positive self-image, which enhances a positive self-esteem and self-confidence further. Self-Categorization and a sense of belonging is instilled, which further invents the cycle for positive self-image and self-esteem. This has been identified in interdisciplinary relationships, which further builds upon the self-concept of the student nurse.

A positive self-esteem was motivated by the in-group members in enhancing the image of nursing. They felt a sense of safety when internalizing the professions' identity through group dynamics, but was still in the process of developing a self-concept. Senior students on the other hand developed a negative and positive self-concept, due to having other degrees they did not give much attention to public image. This could be related to a positive self-concept or opting to another career, or continue in nursing. Intern nurses perceived a positive self-concept and motivated a shared self-image and self-esteem, as opposed to junior and senior students, who were still self-evaluating their new experiences. Students with children identified more stability during the educational process and were ready to adopt a professional role as opposed to students with no children. In summary, nursing students are in the evolvement of a professional identity, but various factors may obstruct or facilitate the progression from self-presenting to a self-concept development and vice versa, incorporating a cycle of social 
change.

It has been identified that a self-presentation constituted a great significance to this study, followed by a self-image, self-esteem self-categorization and self-concept. Through meta-cognition and social influence, the study explored the nursing attitudes and behavior. Educators, researchers, political leaders and managers should focus on how the groups influence people.

\section{Acknowledgements}

The author is very thankful to all the associated personnel in any reference that contributed in/for the purpose of this research.

\section{Source of Funding}

This research is not funded through any source.

\section{Competing Interests Statement}

The author declares that there are no competing or potential conflicts of interest.

\section{References}

Abdelal, R., Herrera, Y. M., Johnston, A. I., \& Martin, T. (2001, August). Treating identity as a variable: measuring the content, intensity, and contestation of identity. In American Political Science Association.

Adams, D., \& Miller, B. K. (2001). Professionalism in nursing behaviors of nurse practitioners. Journal of Professional Nursing, 17(4), 203-210. https://doi.org/10.1053/jpnu.2001.25913

Al-Ahmadi, H. (2014). Anticipated nurses' turnover in public hospitals in Saudi Arabia. The International Journal of Human Resource Management, 25(3), 412-433. https://doi.org/10.1080/09585192.2013.792856

Baraz-Pordanjani, S., Memarian, R., \& Vanaki, Z. (2014). Damaged professional identity as a barrier to Iranian nursing students' clinical learning: a qualitative study. Journal of Clinical Nursing and Midwifery, 3(3), 1-15.

Brooks, J. A., \& Kleine-Kracht, A. E. (1983). Evolution of a definition of nursing. Advances in Nursing Science, 5(4), 51-85. https://doi.org/10.1097/00012272-198307000-00009

Crigger, N., \& Godfrey, N. (2014). From the inside out: A new approach to teaching professional identity formation and professional ethics. Journal of Professional Nursing, 30(5), 376-382. https://doi.org/10.1016/j.profnurs.2014.03.004

Ellemers, N., \& Haslam, S. A. (2011). Social identity theory. Handbook of theories of social psychology, 2, 379-398. https://doi.org/10.4135/9781446249222.n45

Felstead, I. (2013). Role modelling and students' professional development. British Journal of Nursing, 22(4). https://doi.org/10.12968/bjon.2013.22.4.223

Fielden, J. M. (2012). Managing the transition of Saudi new graduate nurses into clinical practice in the Kingdom of Saudi Arabia. Journal of nursing management, 20(1), 28-37. https://doi.org/10.1111/j.1365-2834.2011.01348.x

Franco, M., \& Tavares, P. (2013). The influence of professional identity on the process of nurses' training: an empirical study. Leadership in Health Services, 26(2), 118-134. https://doi.org/10.1108/17511871311319713

Hao, Y. F., Niu, H. J., Li, L. P., Yue, S. J., \& Liu, X. H. (2014). Measurement of professional identity in Chinese nursing students. International Journal of Nursing Sciences, 1(2), 137-144. https://doi.org/10.1016/j.ijnss.2014.05.002

Hewstone, M., \& Brown, R. (1986). Contact is not enough: An intergroup perspective on the'contact hypothesis.' .

Hoeve, Y. T., Jansen, G., \& Roodbol, P. (2014). The nursing profession: public image, self - concept and professional identity. A discussion paper. Journal of advanced nursing, 70(2), 295-309. https://doi.org/10.1111/jan.12177

Larson, J., Brady, M., Engelmann, L., Perkins, B. I., \& Shultz, C. (2013). The formation of professional identity in nursing. Nursing education perspectives, 34(2), 138.

McEwen, M., \& Wills, E. M. (2002). Theoretical basis for nursing. International Journal of Nursing Practice, 20(2), 164-169.

Mebrouk, J. (2008). Perception of nursing care: views of Saudi Arabian female nurses. Contemporary Nurse, 28(1-2), 149-161. https://doi.org/10.5172/conu.673.28.1-2.149 
Moola, S. (2017). Crafting, Constructing and Developing a Nurses' Professional Identity Scale (NPIS). 9(8), 21-31.

Nishisato, S. (1980). Analysis of Categoncal Data: Dual Scaling and Its Applications. Toronto: University of Toronto Press.

Reid, A., Dahlgren, L. O., Petocz, P., \& Dahlgren, M. A. (2008). Identity and engagement for professional formation. Studies in Higher Education, 33(6), 729-742. https://doi.org/10.1080/03075070802457108

Roberts, S. J. (2000). Development of a positive professional identity: Liberating oneself from the oppressor within. Advances in Nursing Science, 22(4), 71-82. https://doi.org/10.1097/00012272-200006000-00007

Tajfel, H., \& Turner, J. C. (1979). An integrative theory of intergroup conflict. The social psychology of intergroup relations, 33(47), 74.

Tajfel, H., \& Turner, J. C. (1986). The social identity theory of inter group behavior. In S. Worchel, \& W. G. Austin (Eds.), Psychology of intergroup relations. Chicago: Nelson.

ten Dam, G. T., \& Blom, S. (2006). Learning through participation. The potential of school-based teacher education for developing a professional identity. Teaching and teacher education, 22(6), 647-660. https://doi.org/10.10802619760902756020

Tzeng, H. M. (2006). Testing a conceptual model of the image of nursing in Taiwan. International journal of nursing studies, 43(6), 755-765. https://doi.org/10.1016/j.ijnurstu.2005.10.004

Willetts, G., \& Clarke, D. (2014). Constructing nurses' professional identity through social identity theory. International journal of nursing practice, 20(2), 164-169. https://doi.org/10.1111/ijn.12108

\section{Copyrights}

Copyright for this article is retained by the author(s), with first publication rights granted to the journal.

This is an open-access article distributed under the terms and conditions of the Creative Commons Attribution license (http://creativecommons.org/licenses/by/4.0/). 